\title{
Blood metabolites as predictors to evaluate the body condition of Neopelma pallescens (Passeriformes: Pipridae) in northeastern Brazil
}

\author{
Luane M.M. Azeredo ${ }^{1 *}$, Talita C. Oliveira ${ }^{1} \&$ Luiz C.S. Lopez ${ }^{2}$
}

\author{
1 Programa de Pós-Graduação em Ciências Biológicas - Zoologia, Universidade Federal da Paraíba. Campus I, \\ Cidade Universitária, Castelo Branco, 58051-900 João Pessoa, PB, Brazil. \\ ${ }^{2}$ Departamento de Sistemática e Ecologia, Centro de Ciências Exatas e da Natureza, Universidade Federal da \\ Paraíba. Campus I, Cidade Universitária, Castelo Branco, 58051-900 João Pessoa, PB, Brazil. \\ *Corresponding author e-mail: luaneazeredo@gmail.com
}

\begin{abstract}
Body condition is an important ecological attribute that can provide a measure of the energy stored by an animal or population. Body condition is traditionally ascertained with morphometric body condition indices ( $\mathrm{BCls}$ ), but some researchers have used various physiological and biochemical parameters as predictors of body condition. This study aimed to test reliable biochemical predictors of body condition in individuals of Neopelma pallescens (Lafresnaye, 1853), found in an Atlantic forest patch. For this purpose we examined the relationship between body condition and the concentrations of blood glucose and ketones. We also verified correlations between blood metabolite concentrations and ecological variables, including time of day, seasons, breeding periods, and ectoparasite infestation. Birds were captured with mist nets at Reserva Biológica de Guaribas, state of Paraíba, Brazil. Blood samples were analyzed with a portable glucometer. The correlation between glucose and ketones was negative. Both metabolites showed significant variations according to time of day. Glucose levels were higher in the afternoon and ketones levels were higher in the morning, suggesting a correlation with daily food intake. The $\mathrm{BCl}$ of non-breeding birds was negatively correlated with glucose concentrations. However, the correlation between glucose and the $\mathrm{BCl}$ of incubating birds was a positive. Ketone bodies did not correlate with body condition. In relation to ectoparasite infestation, only ketones showed significant results, presenting a higher concentration in infested individuals. Glucose is a good predictor of the $\mathrm{BCl}$ of incubating birds since it correlates positively with it. However, the lack of seasonal variations in metabolites indicates that the nutritional status of tropical birds does not change when food is abundant. Thus, we conclude that glucose and ketone bodies can predict the nutritional status of birds but in a context-dependent fashion.
\end{abstract}

KEY WORDS. Birds, ectoparasitism, glucose, incubation, ketones.

Body condition is an important ecological attribute that can provide a measure of the energy stored by an animal or a population. This reserve is usually correlated with biological and ecological factors that are important to environmental conservation (SPEakman 2001, Cattet \& Obbard 2005, Stevenson \& Woods 2006, Labocha \& Hayes 2012). Traditionally, the body condition of an animal is measured using morphometric measurements to calculate body condition indices (BCIs) (LE CREN 1951, Garrow \& Webster 1985, Peig \& Green 2009). However, these BCIs may not be sensitive enough to detect variations in the body condition of animals in habitats that have a constant food supply (JENNI-EIERMANn \& JENNI 1998).

More direct measurements, based on physiological data, are commonly used to assess the health status of an animal. These parameters include hematological tests to check hemo- globin, hematocrits and the ratio of heterophils/limphocytes (SzABO et al. 2002, MACHADO-FILHO et al. 2010), as well as blood chemistry parameters that can indicate the nutritional state of an organism, for instance triglycerides, glucose and ketone bodies (Jenni-EIermann et al. 2002, Costa \& Macedo 2005, KiLGas et al. 2007, Lobato et al. 2011). Besides being more direct, physiological indices can be used in studies with individuals of different ages and different morphometries in a population, since a single morphometric index may not work for the entire population. Thus, physiological parameters seem to be a more reliable technique (STEVENSON \& Woods 2006).

According to (Jenni-Eiermann \& Jenni 1997), daily concentrations of glucose and ketone bodies are directly and inversely proportional to daily food intake, respectively. In vertebrates, glucose serves several functions and is the main energy producer 
(Braun \& Sweazea 2008). When animals go through a fasting period, their organs tend to spare glucose and rather use ketone bodies. Ketone bodies are produced from the breakdown of fatty acids in the liver. They are released into the bloodstream and transported to body tissues to supply glucose requirements (Thompson \& Wu 1991, HegEmann et al. 2012). Therefore, if a bird is hungry or malnourished, the concentration of ketone bodies in its blood will most likely will be high, whereas the concentration of glucose will be low. This relationship may be difficult to demonstrate in animals that inhabit regions where food supply is constant, but not in all cases. For instance, passerines usually spend the entire night fasting, and that short fasting period is sufficient to increase ketone and decrease glucose concentrations (Jenni-Eiermann \& Jenni 1997). Correlations between glucose concentration and body condition have already been described by Minias \& KaCZMAREK (2013) in their study about Phalacrocorax carbo sinensis nestlings (Linnaeus, 1758). Thus, we assume that both metabolites may be suitable body condition indicators because of their relationship to the organism's nutritional state.

Studies on metabolite variations in the blood of birds usually attempt to establish correlations between physiology and ecological variables such as breeding period and ectoparasitism. The breeding period is defined as a phase of higher energy expenditure in the life of a bird. Due to reproduction costs, there can be changes in body condition depending on the adaptive strategies of each species (Monaghan et al. 1989, Moreno 1989, RIECHERT et al. 2014). Some species can spend long periods of fasting during incubation and are dedicated exclusively to the nest (Chaurand \& Weimerskirch 1994, Hollmen et al. 2001). Others tend to increase their foraging activity and are fed by their partners (Lifjeld \& Slagsvold 1986, NiLsson \& Smith 1988, Kern et al. 2005). Thus, since their nutritional status is related to their body condition, we can identify information about the breeding strategies of birds by measuring their metabolites (Hollmen et al. 2001, VleCK \& VleCK 2002, GAYATHRI et al. 2004).

The presence of ectoparasites in birds can also be correlated with their body condition. Those symbionts usually damage their host, which is reflected in their health status (Richner et al. 1993, Hurtrez-Bousses et al. 1997, de Lope et al. 1998). However, some studies demonstrate that the damage caused by ectoparasites is not visible in morphometry, but can be found by physiological data (SzABO et al. 2002, MaCHADO-Filho et al. 2010). There are published studies on the relationship between glucose and ectoparasitism for fish and crustaceans (Grutter \& Pankhurst 2000, Ruane et al. 2000, Neves et al. 2004, DAvies et al. 2015), but not [do much] for birds. Literature data on the correlation between ectoparasite infestation and blood metabolites in birds usually pertain hematocrit, triglycerides, protein and corticosterone (SAINO et al. 1998, SzABO et al. 2002, 2008 Quillfeld et al. 2004, DeEm et al. 2011) This study aimed to test whether glucose and ketone bodies can be reliable biochemical predictors of the body condition of an Atlantic forest passerine. For this purpose we examined the relationship between body condition and the concentrations of blood glucose and ketone bodies. Knowledge about the physiological conditions of wild birds is critical to better understand the adaptive strategies of their survival in nature (CAREY 2005). Therefore, this report verified correlations between blood metabolite concentrations and ecological variables including time of day, seasons, breeding period and ectoparasite infestation.

The species we chose for study was the pale-bellied Tyrant-Manakin, Neopelma pallescens (Lafresnaye, 1853). This bird inhabits the 'cerradão' as well as dry and gallery forests, arboreal 'caatingas', and riparian forests (SigRIST 2009). Despite its distribution through several biomes, there are few studies about the ecology of this passerine or even the genus Neopelma. Neopelma pallescens is primarily insectivorous but also eats some fruit. Thus, it is also a seed disperser.

Small endotherms usually have a high metabolic rate (Beuchat \& Chong 1998). Therefore, their metabolite concentrations vary rapidly during a short period. Due to its small body size and homoeothermic condition, $N$. pallescens can be a suitable model to study metabolite oscillation in the organism (Jenni-Eiermann \& Jenni 1998). We expect to observe oscillations in the metabolites of $N$. pallescens that allow us to better comprehend the ecology of this bird.

Laboratory methods require blood samples to be properly stored and transported to the laboratory for further analysis. To this end, researchers have used portable glucometers (LIESKE et al. 2002, Zeugswetter et al. 2007, Lobban et al. 2010). Such tools are low-cost, easy to use, and require only a single drop of blood. The results are obtained almost immediately. Most zoological studies with glucometers focus on veterinary purposes and captive animals. The use of glucometers in ornithology is still recent (Downs et al. 2010, WitteveEn et al. 2014). Some glucometers are compatible with reagent test strips of glucose and ketones. This can facilitate the researcher's work since only one type of equipment is used.

There are few studies about physiological body condition indices based on glucose and ketone bodies for wild birds in the Neotropical region - especially passerines. Previous studies in South America have used only free-living waterfowls (ARTACHO et al. 2007, Gallo et al. 2013) and captive psittacines (Allgayer et al. 2009). Thus, the present study is the first to investigate the relationship between blood glucose/ketone body concentrations with ecological variables and body condition in a free-living South American passerine.

\section{MATERIAL AND METHODS}

This study was conducted at Reserva Biológica de Guaribas (Rebio Guaribas) located between the municipalities of Mamanguape and Rio Tinto, in Paraíba, Brazil (6 $44^{\circ} 02$ "S, 35 10'32 “W and $6^{\circ} 40^{\prime} 53$ “S, $\left.35^{\circ} 09^{\prime} 59^{\prime \prime W}\right)$. The climate in Rebio Guaribas is warm and humid with average annual temperature of $26^{\circ} \mathrm{C}$ (AlvAREs et al. 2014). The rainy season occurs from March to August and the dry season from September to February. The seasonality was estimated by the annual precipitation data of the city of Mamanguape from the last five years obtained from the website Proclima. 
The specimens were collected with 10 mist nets in fortnightly expeditions of three days each from January to December of 2014. The mist nets were set up along two trails, and they remained opened during the first and last time of daily activity (from 5AM to 10:00 AM; and from 3:00 PM to 6:00 PM). The sampling effort was calculated according to STRAUBE \& BiANCONI (2002). We checked the nets every twenty minutes using the species-specific song of $N$. pallescens in playback to attract the birds and removed them as soon they were caught. Walking to the laboratory to transport the birds caught in containment bags took about 15 minutes. All individuals were banded with metallic rings provided by CEMAVE.

One drop of blood (licensed 41816-1 granted by SISBIO - ICMBio) was collected from the brachial vein of the birds' wings using disposable calibrated lancets GTech ${ }^{\circledR}$ inserted into a lancing device GTech ${ }^{\circledR}$. The concentrations of glucose and ketone were measured using reagent test strips (Freestyle ${ }^{\circledR}$ ) and a glucometer (Optium ${ }^{\mathrm{TM}}$ Xceed $^{\circledR}$ ). Ideally, multiple blood samples should have been taken consecutively on the same day, but we opted not to do this since it would significantly compromise the blood volume of a small bird such as $N$. pallescens. The resulting low blood volume could interfere with the birds' health status.

We used a body condition index (BCI) to assess the body condition of $N$. pallescens. We evaluated the index using Le Cren's relative condition (Kn) (LE CREN 1951). This index consists of a ratio between the expected body mass and the observed body mass. The expected body mass was assessed using residuals of an ordinary least square (OLS) regression between body mass and the length of the wing of $N$. pallescens.

The breeding period was assessed using the development phases of brood patches. We identified as females all individuals with brood patches, since incubation in the Pipridae family is performed exclusively by females. The early phases (P1 defeathered, smooth and dark; P2- presence of a little fluid, opaque colored) were considered as the start of the incubation period (initial and intermediary phase), but not considered active incubation. The individuals were considered to be in their active incubating phase when the patch was supplied by the blood vessels (P3) (IBAMA-adapted 1994). We classified the individuals as infested or non-infested by ectoparasites to investigate the variation of metabolite concentration according to the presence or absence of ectoparasites. The time spent searching for ectoparasites was the same for all individuals (5 minutes). We also manually collected ectoparasite samples for identification.

We employed a stepwise model selection using the Akaike's information criterion (AIC) to select the model that best fits the relationship between metabolites and all ecological variables (time of day, months of the year, rainy and dry seasons, prevalence of ectoparasites and breeding period). The best model was then employed in a generalized linear model (GLM) to examine the contribution of each variable. The data were normalized by logarithm transformation before performing GLM.

Further analyses were performed using parametric or non-parametric tests depending on the normality results from Shapiro-Wilking's test and heteroscedasticity Levene's test. The relationship between metabolites and non-selected ecological variables were considered non-significant. We used analysis of variance (ANOVA) followed by Tukey's test to clarify the relationship between metabolites and breeding period. We also used correlation tests to analyze the relationship between metabolites and BCI. We adopted a 95\% confidence interval ( $\mathrm{p}<0.05$ ); all analyses used R version 3.0.3 (R CORE TEAM 2014).

\section{RESULTS}

The sampling effort was $103.680 \mathrm{~h}^{*} \mathrm{~m}^{2}$. A total of $102 \mathrm{in}$ dividuals of $N$. pallescens were captured and 28 were recaptured. We removed the recaptured individuals from analyses, resulting in a sample with 74 individuals, 74 blood glucose samples and 50 blood ketone samples (the ketone test strips were not available for purchase during a two-month period). Twenty-eight of the captured individuals had brood patches: 19 presented a brood patch in P1, six in P2 and only three in P3. Sixty-four individuals were infested with parasites, 56 were infested with feather mites, 40 were infested with chewing lice and 31 individuals were infested with both.

The model that best fits the relationship between glucose and ecological variables was the one that included breeding period, time of day and BCI. The final stepwise model for the relationship between ketone concentration and ecological variables showed that the best fit model included time of day, breeding period and chewing lice infestation (Table 1). The time of capture of $N$. pallescens influenced the concentrations of both metabolites. The concentration of glucose $(\mathrm{mmol} / \mathrm{L})$ varied sig-

Table 1. Summary of GLMs showing the relationship between the metabolites concentration and the variables selected by AIC stepwise model selection for N. pallescens in Reserva Biológica de Guaribas, PB.

\begin{tabular}{|c|c|c|c|c|c|c|c|c|c|}
\hline \multirow{2}{*}{ Variables } & \multicolumn{4}{|c|}{ Glucose } & \multirow{2}{*}{ Variables } & \multicolumn{4}{|c|}{ Ketones } \\
\hline & Estimate & Std. Error & $\mathrm{t}$ value & $\mathrm{p}$-value & & Estimate & Std. Error & $\mathrm{t}$ value & $\mathrm{p}$-value \\
\hline Intercept & 27.5092 & 4.3109 & 6.381 & $<0.001$ & Intercept & 1.59218 & 0.122289 & 12.956 & $<0.0010$ \\
\hline Time of day [afternoon] & 2.0841 & 0.9785 & 2.130 & 0.037 & Time of day [morning] & 0.38112 & 0.180290 & -2.114 & 0.0406 \\
\hline Breeding period [P1] & -2.0759 & 1.0650 & -1.949 & 0.055 & Breeding period [P1] & -0.38683 & 0.199720 & 1.937 & 0.0597 \\
\hline Breeding period [P2] & -0.7884 & 1.6935 & -0.466 & 0.643 & Breeding period [P2] & 0.04555 & 0.312220 & 0.146 & 0.8847 \\
\hline Breeding period [P3] & 4.6519 & 2.3706 & 1.962 & 0.044 & Breeding period [P3] & 0.36441 & 0.376820 & 0.967 & 0.3392 \\
\hline Body Condition Index & -9.0580 & 4.3045 & -2.104 & 0.039 & Chewing lice infestation [infested] & 0.47603 & 0.180290 & 2.640 & 0.0117 \\
\hline
\end{tabular}


nificantly with the bird's time of capture and was higher during the afternoon (Table 1$)$. Ketone concentrations ( $\mathrm{mmol} / \mathrm{L})$ were higher in the morning (Table 1). The Spearman's correlation between glucose and ketones showed that these metabolites are negatively correlated with each other $(\mathrm{S}=31843.73$, rho $=$ $-0.53, \mathrm{p}<0.01$ ) (Fig. 1).

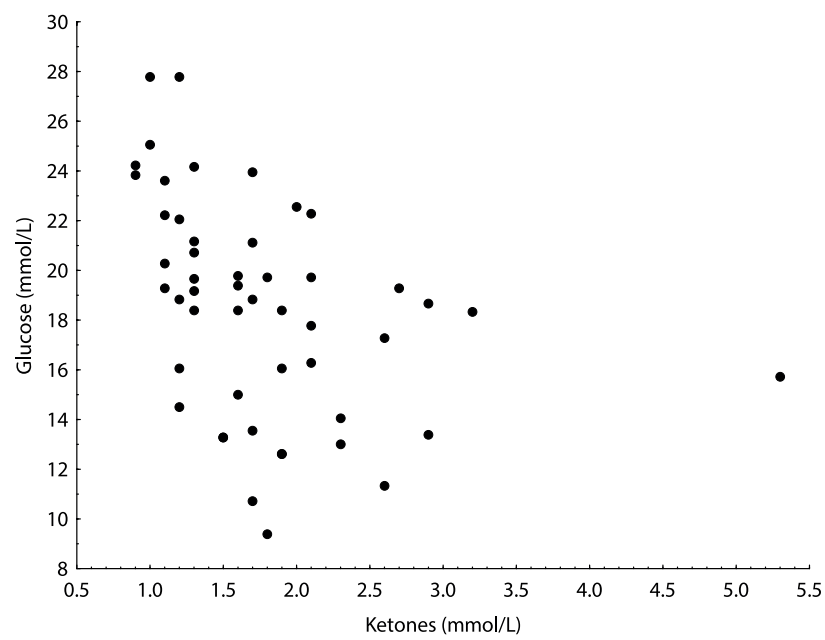

Figure 1. Spearman's correlation between glucose and ketones concentration of individuals of $N$. pallescens in Reserva Biológica de Guaribas, PB. $\mathrm{N}=50$.

The rainy season is from March to August, and the dry season is from September to February. None of the metabolites showed a significant variation among the months, nor among the seasons. The monthly sample sizes are described in Fig. 2.

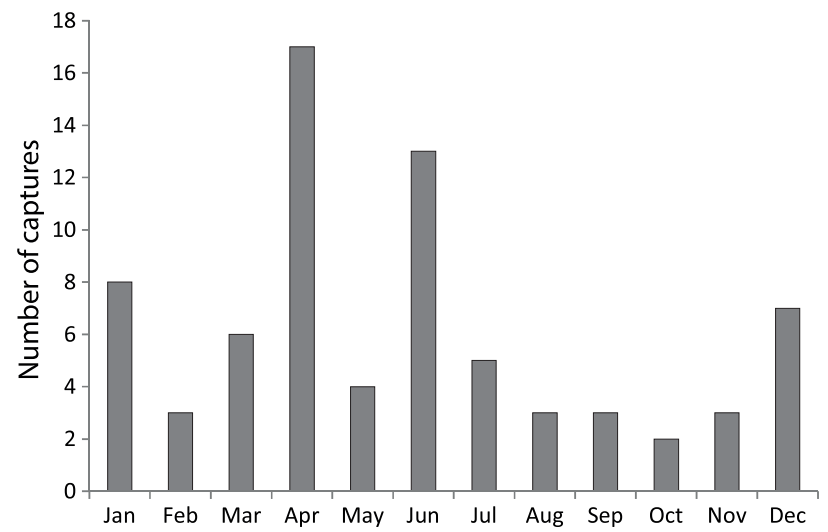

Figure 2. Monthly samples sizes of captured individuals of $N$. pallescens in Reserva Biológica de Guaribas, PB. Recaptured individuals are not included.

The glucose concentration was negatively correlated with body condition (Table 1). Further analyses showed that the glu- cose of non-breeding birds was negatively correlated with their BCI $(S=21242.05$, rho:-0.31, p-value $=0.03)$ (Fig. 3). However, a correlation between BCI and glucose concentration -including only those individuals with brood patches (28) - showed a positive and significant correlation $(\mathrm{S}=2095.15$, rho $=0.42, \mathrm{p}=$ 0.02 ) (Fig. 4). The ketone concentration and the breeding period presented a non-significant correlation (Table 1).
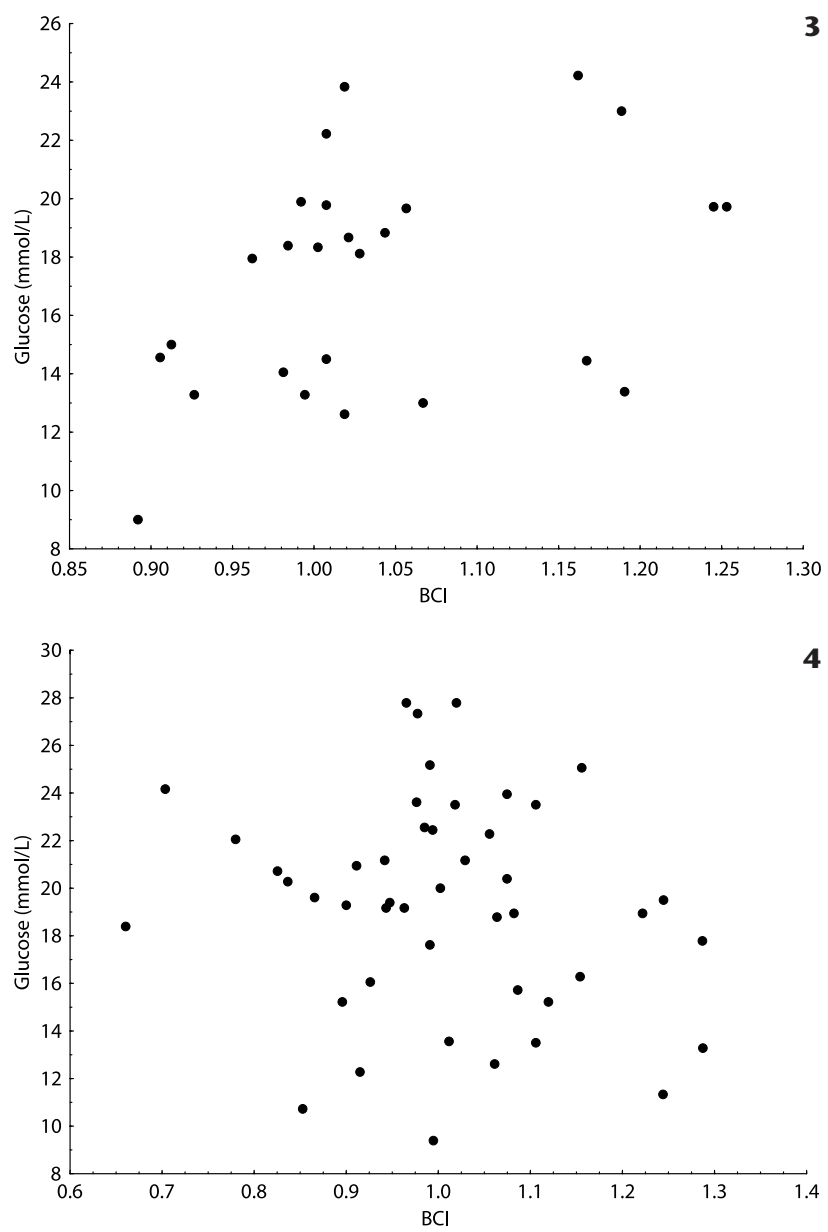

Figures 3-4. Spearman's correlation between Body Condition Index $(\mathrm{BCl})$ and glucose concentration for breeding (3) $(\mathrm{N}=28)$ and non-breeding (4) $(N=46)$ individuals of $N$. pallescens in Reserva Biológica de Guaribas, PB.

The breeding period of $N$. pallescens started at the end of July (P1) and climaxed in January (P3). It occurred throughout the rainy and dry seasons. Glucose concentrations showed significant variation during the developmental phases of brood patches with a higher concentration in P3 (Fig. 5) (ANOVA, F $=5.39, \mathrm{p}=0.01)$. Tukey's test showed significant values only between P1 and P3 (Tukey's Test, P2-P1: p = 0.76, P3-P1 = 0.01, P3-P2: $p=0.05$ ) 


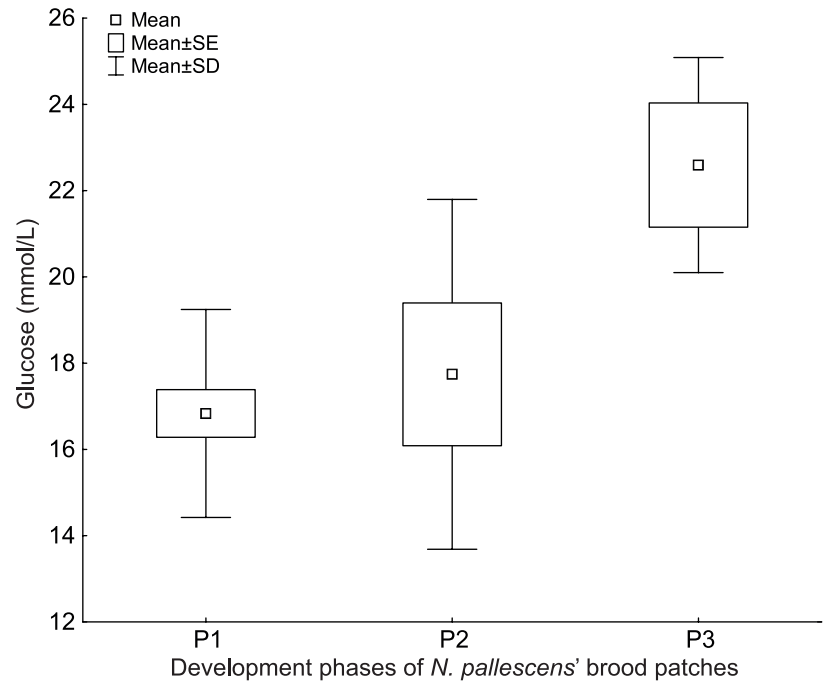

Figure 5. Glucose concentration along the developmental phases of brood patches of $N$. pallescens in Reserva Biológica de Guaribas, PB.

The ectoparasites found in N. pallescens were identified as chewing lice (Phitiraptera: Amblycera: Menoponidae) and feather mites (Acari: Astigmata: Analgoidea). Individuals infested with chewing lice had higher ketone body concentrations (Table 1). Glucose concentration did not present a significant relationship with lice infestation. Neither metabolite concentration varied with feather mite infestation.

\section{DISCUSSION}

Glucose concentration in the blood of N. pallescens increased during the day. This result reflects what is expected for diurnal birds like N. pallescens, which consume food throughout the day. Many studies have described glucose variation in birds (Ferrer et al. 1994, Jenni-Eiermann \& Jenni 1997, Remage-Healey $\&$ Romero 2000). They also demonstrated similar results as this study - an increase in glucose during the day. Those analyses, however, were conducted using laboratory methods. Our results corroborate Downs et al. (2010), LobBAn et al. (2010), WitTEveEN et al. (2014), who used portable glucometers to study glycemia in African birds. Those experiments found an increase in the concentration of glucose during the day (when birds were feeding) and a decrease during the night (when birds were fasting).

Throughout the day, the variation in the concentration of ketones in the blood of $N$. pallescens was inversely proportional to glucose concentration. A higher ketone concentration was found during the morning; ketone levels declined in the afternoon. This can be explained by the fact that $N$. pallescens fasts during the night, which results in ketone concentration increasing during this time. Similar results were observed by JENni-Eiermann \& Jenni (1991, 1994) and Gerson \& Guglielmo (2013) for small passerines in North America and Europe. The ketone concentration described in their studies was also associated with a fasting period.

The negative correlation between glucose and ketone concentrations seems to confirm the relationship between those metabolites. The glucose that is produced in the organism provides energy to many tissues such as the brain. During the fasting period, glucose must be spared. Since glucose is the first primary source of energy for animals, the complete consumption of this metabolite would be incompatible with survival. Thus, the liver releases ketone bodies from the chemical breakdown of fatty acids, which supplies glucose to the organism (THомpson \& Wu 1991, Hegemann et al. 2012). This study was the first to describe this kind of correlation for a South American passerine in natural conditions.

The monthly sample sizes were very small in some months, so the test had low statistical power. The seasonal variations found in this research were similar to those in the study of Morais et al. (2014), who studied the Neotropical bat Sturnira lilium (Geoffroy, 1810). This bat has a body mass similar to $N$. pallescens, and its glucose concentration levels did not vary, in that study, between the rainy and dry seasons. For birds in temperate regions, the oscillation of metabolites in their organs are frequently related to other factors such as breeding period or migration behavior that can be associated with food shortages (TotZKe et al. 1999, Rintamaki et al. 2003, Box et al. 2010, HegemanN et al. 2012). Our results suggest that the territory of $N$. pallescens provides abundant food year-round. Temporal changes such as rainfall might affect the seasonality of fruits and insects, but food is still constant in tropical habitats. As a result, the bird's nutritional status is not affected.

Despite the lack of significant values for metabolite variation during the seasons, we found a significant oscillation during the incubation period of $N$. pallescens. This period started at the end of the rainy season. In the dry season, the birds were actively incubating (specifically, January). Thus, the breeding period is probably related to other environmental factors such as photoperiod, which might indicate the proper time to breed. It does not follow changes in precipitation. We hypothesize that photoperiod may influence the time of avian reproduction since the active incubation coincides with longer days. Thus, there would be more hours to forage and compensate for the energy spent in parental care. We made this assumption based on the study of REPENNING \& FonTANA (2011) about bird breeding in southern Brazil.

The negative correlation between glucose levels and BCI for non-breeding birds could indicate that a high glucose concentration reflects body condition. However, the ketone concentration presented no correlation with BCI, indicating that the individuals were well fed. Moreover, the body mass of tropical passerines tends to be constant in normal conditions due to the regular food availability (GOULART \& RODRIGUES 2007, Machado-Filho et al. 2010, Cox \& Cresswell 2014), while glucose concentrations can change rapidly over a short period of time 
(Beuchat \& Chong 1998). We presume that, even though the correlation was significant, glucose is not a predictor of body condition in these individuals, since they did not use their fat reserve.

During the breeding period, there was a positive correlation between glucose and BCI. This showed that higher glucose concentrations result in better body conditions. Similar studies showed an increase in body mass and glucose concentrations during this period (MoE et al. 2002, GaYATHRI et al. 2004). During incubation, passerines usually gain mass - probably due to fat deposition and accumulation of fluids for brood patch formation (SICK 1997). Nonetheless, the lack of variation in ketone concentration during this period shows that, even though birds spend lots of energy incubating eggs, they do not use their lipid reserves for that. This result is similar to other studies on ketone concentration in incubating passerines (see KeRN et al. 2005, Done et al. 2011).

The relationship between glucose and BCI in incubating birds indicates that individuals of $N$. pallescens nourish themselves in a way that compensates for the energy required for incubation. Thus, the metabolite variation probably reflects how individuals of the species divide their time between parental care and keeping their own body condition (CHAstel et al. 1995, MOE et al. 2002). In the family Pipridae, only females incubate the eggs (Sick 1997), and our results are probably associated with a particular adaptive strategy of $N$. pallescens. According to Moreno (1989), these birds are not adapted to prolonged fasting and must ocasionally leave the nest to forage because they do not accumulate sufficient body fat to spend the entire incubation on the nest. Similar behaviors are described in the literature for some passerines that also perform uniparental incubation (see LIFJELD \& Slagsvold 1986, Conway \& Martin 2000, Kern et al. 2005, Alvarez \& BARBA 2014). Species that are adapted to prolonged fasting usually store fat to metabolize energy. This increases the concentration of ketones in the blood and decreases body condition (Hollmen et al. 2001, VleCK \& VleCK 2002, RieChERT et al. 2014).

The lack of correlation between metabolites and feather mites probably indicates a non-parasitic relationship between mites and birds. Blanco et al. (1997) suggested that such relationships should be described as mutualistic or commensalistic, because feather mites do not damage the host's body condition. The chewing lice from the Menoponidae family feed exclusively on blood, and they are also permanent parasites (HAMSTRA \& BADYAEV 2009). Our results suggest that the lice may act to the detriment of the host's body condition and might induce the bird to use its lipid reserves. Another possibility is that malnourished birds are more vulnerable to ectoparasite infestations. We did not find studies correlating the concentration of glucose or ketones with the presence of ectoparasites in birds. Thus, this study is most likely the first to describe this correlation between ketone bodies and lice infestation in birds.

Our results offer new information on the ecology of $N$. pallescens by demonstrating that measuring glucose and ketone concentrations are effective means to detect temporal variations in the physiological condition of N. pallescens. Glucose is a good predictor of body condition in incubating birds due to its positive relationship with body condition. However, the lack of metabolite variation among the seasons shows that the nutritional status of tropical birds does not change when food is abundant. Thus, we conclude that glucose and ketone bodies can predict the nutritional status but in a context-dependent fashion. This is analogous to how glucose can predict body condition.

When there is variation in body mass, we observe that glucose is directly correlated with body condition. However, this physiological data is inadequate when body mass is constant. Using this variable as a metric of body condition requires specific knowledge about the relationship between nutritional status and body condition in specific contexts. WILDER et al. (2016) used BCI values, but it may be difficult to assess body condition with this metric because body mass does not always reflect the energy reserve of an animal. Thus more direct measures of body composition like fatty acids are suitable. We conclude that the relationship between BCI and these physiological variables may be complex or absent, which requires more investigation. This suggests that further studies should investigate the relationship between ketone concentration and chewing lice infestation.

Portable glucometers are useful to study wild birds. The Optium Xceed ${ }^{\circledR}$ medisense has been already validated to measure ketoacidosis for dairy cows (Voyvoda \& ERdogan 2010) and glucose for horses (Peugnet 2014). Our data could not be validated versus a laboratory-based system because of the low blood volumes available in birds. Another question is that we have no information about the repeatability of the assays because we measured the blood metabolites in simplicates. While we observed metabolite variation similar to other studies, we do not for certain how our 'assay compares with laboratory results.

\section{ACKNOWLEDGMENTS}

We thank SISBIO - ICMBio for the license that allowed this study to be conducted. We also thank Jorge Nascimento (Julião) and Getulio Freitas managers of the Reserva Biológica de Guaribas - PB, for their logistical support. In addition, we are grateful to Alan L. Ribeiro, for the metallic rings from CEMAVE. This research was undertaken during the master's dissertation of LMMA. Lastly, we thank the Programa de Pós-graduação em Ciências Biológicas - Zoologia (PPGCB) from Universidade Federal da Paraíba - UFPB, and Capes for Master's scholarship.

\section{LITERATURE CITED}

Allgayer MC, Guedes NMr, Chiminazzo C, Cziulik M, Weimer TA (2009) Clinical pathology and parasitologic evaluation of free-living nestlings of the hyacinth macaw (Anodorhynchus hyacinthinus). Journal of Wildlife Diseases 45: 972-981. doi: 10.7589/0090-3558-45.4.972 
Alvares CA, Stape JL, Sentelhas PC, Goncalves JLD, Sparovek G (2014) Koppen's climate classification map for Brazil. Meteorologische Zeitschrift 22: 711-728. doi: 10.1127/09412948/2013/0507

Alvarez E, Barba E (2014) Within and between population variations of incubation rhythm of great tits Parus major. Behaviour 151: 1827-1845. doi: 10.1163/1568539x-00003218

Artacho P, Soto-Gamboa M, Verdugo C, Nespolo RF (2007) Blood biochemistry reveals malnutrition in black-necked swans (Cygnus melanocoryphus) living in a conservation priority area. Comparative Biochemistry and Physiology a-Molecular \& Integrative Physiology 146: 283-290. doi: 10.1016/j. cbpa.2006.10.031

Beuchat CA, Chong CR (1998) Hyperglycemia in hummingbirds and its consequences for hemoglobin glycation. Comparative Biochemistry and Physiology a-Molecular and Integrative Physiology 120: 409-416. doi: 10.1016/s10956433(98)10039-9

Blanco G, Tella JL, Potti J (1997) Feather mites on group-living Red-billed Choughs: a non-parasitic interaction? Journal of Avian Biology 28: 197-206. doi: 10.2307/3676970

Box J, LiLL A, BALDWIN J (2010) Is there seasonal variation in stored energy reserves and catabolic enzyme activities in Superb fairy-wrens? Avian Biology Research 3: 107-114. doi: 10.3 184/175815510x12823045556835

Braun EJ, Sweazea KL (2008) Glucose regulation in birds. Comparative Biochemistry and Physiology B-Biochemistry \& Molecular Biology 151: 1-9. doi: 10.1016/j.cbpb.2008.05.007

CAREY C (2005) How physiological methods and concepts can be useful in conservation biology. Integrative and Comparative Biology 45: 4-11. doi: 10.1093/icb/45.1.4

CATTET MRL, ObBaRd ME (2005) To weigh or not to weigh: conditions for the estimation of body mass by morphometry. Ursus 16: 102-107. doi: 10.2192/1537-6176(2005)016[0102:twontw]2.0. $\mathrm{CO} ; 2$

Chastel O, Weimerskirch H, Jouventin P (1995) Body condition and seabird reproductive-performance - a study of 3 petrel species. Ecology 76: 2240-2246. doi: 10.2307/1941698

Chaurand T, Weimerskirch H (1994) Incubation routine, bodymass regulation and egg neglect in the blue petrel Halobaena caerulea. Ibis 136: 285-290. doi: 10.1111/j.1474-919X.1994. tb01097.x

Conway CJ, Martin TE (2000) Evolution of passerine incubation behavior: Influence of food, temperature, and nest predation. Evolution 54: 670-685.

Costa FJV, MAcedo RH (2005) Coccidian oocyst parasitism in the blue-black grassquit: influence on secondary sex ornaments and body condition. Animal Behaviour 70: 1401-1409. doi: 10.1016/j.anbehav.2005.03.024

Cox DTC, Cresswell W (2014) Mass gained during breeding positively correlates with adult survival because both reflect life history adaptation to seasonal food availability. Oecologia 174: 1197-1204. doi: 10.1007/s00442-013-2859-5
Davies CE, Vogan CL, Rowley AF (2015) Effect of the copepod parasite Nicothoe astaci on haemolymph chemistry of the European lobster Homarus gammarus. Diseases of Aquatic Organisms 113: 169-175. doi: 10.3354/dao02814

de Lope F, Moller AP, de la Cruz C (1998) Parasitism, immune response and reproductive success in the house martin Delichon urbica. Oecologia 114: 188-193. doi: 10.1007/s004420050435

Deem SL, Parker PG, Cruz MB, Merkel J, Hoeck PEA (2011) Comparison of blood values and health status of floreana mockingbirds (Mimus trifasciatus) on the islands of champion and gardner-by-floreana, galapagos islands. Journal of Wildlife Diseases 47: 94-106. doi: 10.7589/0090-3558-47.1.94

Done T, Gow EA, Stutchiury BJM (2011) Corticosterone stress response and plasma metabolite levels during breeding and molt in a free-living migratory songbird, the wood thrush (Hylocichla mustelina). General and Comparative Endocrinology 171: 176-182. doi: 10.1016/j.ygcen.2011.01.006

Downs CT, Wellmann AE, Brown M (2010) Diel variations in plasma glucose concentrations of Malachite Sunbirds Nectarinia famosa. Journal of Ornithology 151: 235-239. doi: 10.1007/ s10336-009-0439-6

Ferrer M, Amat JA, Vinuela J (1994) Daily variations of blood-chemistry values in the chinstrap penguin (Pygoscelis antarctica) during the antarctic summer. Comparative Biochemistry and Physiology a-Physiology 107: 81-84. doi: 10.1016/0300-9629(94)90277-1

Gallo L, Quintana F, Svagelj WS, Uhart M (2013) Hematology and blood chemistry values in free-living Imperial Cormorants (Phalacrocorax atriceps). Avian Diseases 57: 737-743. doi: 10.1637/10521-022713-Reg.1

Garrow JS, Webster J (1985) Quetelet index (w/h-2) as a measure of fatness. International Journal of Obesity 9: 147-153.

Gayathri KL, Shenoy KB, Hegde SN (2004) Blood profile of pigeons (Columba livia) during growth and breeding. Comparative Biochemistry and Physiology a-Molecular \& Integrative Physiology 138: 187-192. doi: 10.1016/j.cbpb.2004.03.013

Gerson AR, Guglielmo CG (2013) Energetics and metabolite profiles during early flight in American robins (Turdus Migratorius). Journal of Comparative Physiology B-Biochemical Systemic and Environmental Physiology 183: 983-991. doi: 10.1007/s00360-013-0767-y

Goulart FF, Rodrigues M (2007) Daily and seasonal deposition of subcutaneous fat in Phacellodomus rufifrons, a Neotropical ovenbird. Revista Brasileira de Zoologia 24: 535-540. doi: 10.1590/s0101-81752007000300002

Grutter AS, PANKhurst NW (2000) The effects of capture, handling, confinement and ectoparasite load on plasma levels of cortisol, glucose and lactate in the coral reef fish Hemigymnus melapterus. Journal of Fish Biology 57: 391-401. doi: 10.1006/jfbi.2000.1312

Hamstra TL, BADyaev AV (2009) Comprehensive investigation of ectoparasite community and abundance across life history stages of avian host. Journal of Zoology 278: 91-99. doi: 10.1111/j.1469-7998.2008.00547.x 
Hegemann A, Matson KD, Versteegh MA, Tieleman BI (2012) Wild skylarks seasonally modulate energy budgets but maintain energetically costly inflammatory immune responses throughout the annual cycle. Plos One 7. doi: 10.1371/ journal.pone.0036358

Hollmen T, Franson JC, Hario M, Sankari S, Kilpi M, Lindstrom K (2001) Use of serum biochemistry to evaluate nutritional status and health of incubating common eiders (Somateria mollissima) in Finland. Physiological and Biochemical Zoology 74: 333-342. doi: 10.1086/320421

Hurtrez-Bousses S, Perret P, Renaud F, Blondel J (1997) High blowfly parasitic loads affect breeding success in a Mediterranean population of blue tits. Oecologia 112: 514-517. doi: 10.1007/s004420050339

IBAMA (1994) Manual de Anilhamento de Aves Silvestres. Brasília, Centro de Pesquisas para a Conservação de Aves Silvestres, Instituto Brasileiro do Meio Ambiente.

Jenni-Eiermann S, Jenni L (1991) Metabolic responses to flight and fasting in night-migrating passerines. Journal of Comparative Physiology B-Biochemical Systemic and Environmental Physiology 161: 465-474.

Jenni-Eiermann S, Jenni L (1994) Plasma metabolite levels predict individual body-mass changes in a small long-distance migrant, the garden-warbler. Auk 111: 888-899.

Jenni-Eiermann S, Jenni L (1997) Diurnal variation of metabolic responses to short-term fasting in passerine birds during the postbreeding, molting and migratory period. Condor 99: 113-122. doi: $10.2307 / 1370229$

JenNi-EieRMAnN S, JeNni L (1998) What can plasma metabolites tell us about the metabolism, physiological state and condition of individual birds? An overview. Biologia e Conservazione della Fauna 102: 312-319.

Jenni-Eiermann S, Jenni L, Kvist A, Lindstrom A, Piersma T, Visser GH (2002) Fuel use and metabolic response to endurance exercise: a wind tunnel study of a long-distance migrant shorebird. Journal of Experimental Biology 205: 2453-2460.

Kern M, Bacon W, Long D, Cowie RJ (2005) Blood metabolite and corticosterone levels in breeding adult Pied Flycatchers. Condor 107: 665-677. doi: 10.1650/0010-5422(2005)107[0665:bmacli]2.0.co;2

Kilgas P, Tilgar V, Maegi M, Maend R (2007) Physiological condition of incubating and brood rearing female Great Tits Parus major in two contrasting habitats. Acta Ornithologica 42: 129-136. doi: 10.3161/068.042.0207

Labocha MK, HaYes JP (2012) Morphometric indices of body condition in birds: a review. Journal of Ornithology 153: 1-22. doi: 10.1007/s10336-011-0706-1

LE CREN ED (1951) The length-weight relationship and seasonal cycle in gonad weight and condition in the perch (Perca fluviatilis). Journal of Animal Ecology 20: 201-219. doi: $10.2307 / 1540$

Lieske CL, Ziccardi MH, Mazet JAK, Newman SH, Gardner IA (2002) Evaluation of 4 handheld blood glucose monitors for use in seabird rehabilitation. Journal of Avian Medicine and Surgery 16: 277-285. doi: 10.1647/1082-6742(2002)016[0277:eohbgm]2.0.co;2

Lifjeld JT, Slagsvold T (1986) The function of courtship feeding during incubation in the pied flycatcher Ficedula hypoleuca. Animal Behaviour 34: 1441-1453. doi: http://10.1016/ S0003-3472(86)80215-9

Lobato DNC, Braga EM, Belo NdO, Antonini Y (2011) Hematological and parasitological health conditions of the Pale-breasted Thrush (Turdus leucomelas) (Passeriformes: Turdidae) in southeastern Brazil. Zoologia 28: 771-776. doi: 10.1590/ s1984-46702011000600010

Lobban K, Downs C, Brown M (2010) Diel variations in plasma glucose concentration in some South African avian frugivores. Emu 110: 66-70. doi: 10.1071/mu09088

Machado-Filho RAN, Balsamao GM, Marini MA (2010) Seasonal differences in immune profiles and body conditions of migratory and permanent resident neotropical flycatchers. Condor 112: 579-590. doi: 10.1525/cond.2010.090146

Minias P, Kaczmarek K (2013) Is it always beneficial to breed in the centre? Trade-offs in nest site selection within the colony of a tree-nesting waterbird. Journal of Ornithology 154: 945-953. doi: 10.1007/s10336-013-0960-5

Moe B, Langseth I, Fyhn M, Gabrielsen GW, Bech C (2002) Changes in body condition in breeding kittiwakes Rissa tridactyla. Journal of Avian Biology 33: 225-234. doi: 10.1034/j.1600048X.2002.330304.X

Monaghan P, Uttley JD, Burns MD, Thaine C, Blackwood J (1989) The relationship between food-supply, reproductive effort and breeding success in arctic terns sterna-paradisaea. Journal of Animal Ecology 58: 261-274. doi: 10.2307/4999

Morais DB, Barros MS, Freitas MBD, Pinto Da Matta SL (2014) Seasonal assessment of the reproductive cycle and energy reserves of male bats Sturnira lilium (Chiroptera: Phyllostomidae). Journal of Mammalogy 95: 1018-1024. doi: 10.1644/14-mamm-a-080

Moreno J (1989) Strategies of mass change in breeding birds. Biological Journal of the Linnean Society 37: 297-310. doi: 10.1111/j.1095-8312.1989.tb01907.x

Neves CA, Pastor MPS, Nery LEM, Santos EA (2004) Effects of the parasite Probopyrus ringueleti (Isopoda) on glucose, glycogen and lipid concentration in starved Palaemonetes argentinus (Decapoda). Diseases of Aquatic Organisms 58: 209-213. doi: 10.3354/dao058209

NiLsson J-Å, Smith HG (1988) Incubation feeding as a male tactic for early hatching. Animal Behaviour 36: 641-647. doi: 10.1016/S0003-3472(88)80145-3

Peig J, Green AJ (2009) New perspectives for estimating body condition from mass/length data: the scaled mass index as an alternative method. Oikos 118: 1883-1891. doi: 10.1111/j.1600-0706.2009.17643.x

Quillfeldt P, Masello JF, Mostl E (2004) Blood chemistry in relation to nutrition and ectoparasite load in Wilson's 
storm-petrels Oceanites oceanicus. Polar Biology 27: 168-176. doi: 10.1007/s00300-003-0572-2

Peugnet P, Wimel L, Duchamp G, Sandersen C, Camous S, Guillaume D, Dahirel M, Dubois C, Jouneau L, Reigner F, Berthelot V, Chaffaux S, Tarrade A, Serteyn D (2014) Enhanced or reduced fetal growth induced by embryo transfer into smaller or larger breeds alters post-natal growth and metabolism in pre-weaning horses. PLoS ONE 9: 1-13. doi: 10.1371/journal.pone.0102044

R CORE TEAM (2014) R: A language and environment for statistical computing. Vienna, R Foundation for Statistical Computing, available online at: https://www.R-project.org

Remage-Healey L, Romero LM (2000) Daily and seasonal variation in response to stress in captive starlings (Sturnus vulgaris): Glucose. General and Comparative Endocrinology 119: 60-68. doi: 10.1006/gcen.2000.7492

Repenning M, Fontana CS (2011) Seasonality of breeding, moult and fat deposition of birds in subtropical lowlands of southern Brazil. Emu 111: 268-280. doi: 10.1071/mu10018

Richner H, Oppliger A, Christe P (1993) Effect of an ectoparasite on reproduction in great tits. Journal of Animal Ecology 62: 703-710. doi: 10.2307/5390

Riechert J, Chastel O, BeCKer PH (2014) Regulation of breeding behavior: do energy-demanding periods induce a change in prolactin or corticosterone baseline levels in the common tern (Sterna hirundo)? Physiological and Biochemical Zoology 87: 420-431. doi: 10.1086/675682

Rintamaki PT, Stone JR, Lundberg A (2003) Seasonal and diurnal body-mass fluctuations for two nonhoarding species of Parus in Sweden modeled using path analysis. Auk 120: 658-668. doi: 10.1642/0004-8038(2003)120[0658:sadbff]2.0.co;2

Ruane NM, Nolan DT, Rotllant J, Costelloe J, Bonga SEW (2000) Experimental exposure of rainbow trout Oncorhynchus mykiss (Walbaum) to the infective stages of the sea louse Lepeophtheirus salmonis (Kroyer) influences the physiological response to an acute stressor. Fish \& Shellfish Immunology 10: 451-463. doi: 10.1006/fsim.1999.0260

Saino N, Calza S, Moller AP (1998) Effects of a dipteran ectoparasite on immune response and growth trade-offs in barn swallow, Hirundo rustica, nestlings. Oikos 81: 217-228. doi: $10.2307 / 3547043$

SICK H (1997) Ornitologia brasileira. Rio de Janeiro, Nova Fronteira, 912p.

SIGRIST T (2009) Guia de campo Avis brasilis - Avifauna brasileira. Vinhedo, Avis Brasilis Editora, vol. I, 480p, vol. II, 600p.

SPEAKMAN J (2001) Body composition analysis of animals: a handbook of non-destructive methods. Cambridge, Cambridge University Press, 252p.

Stevenson RD, Woods JR WA (2006) Condition indices for conservation: new uses for evolving tools. Integrative and Comparative Biology 46: 1169-1190. doi: 10.1093/icb/icl052
Straube FC, Bianconi GV (2002) Sobre a grandeza e a unidade utilizada para estimar esforço de captura com utilização de redes-de-neblina. Chiroptera Neotropical 8: 150-152.

SZabo K, Szalmas A, LiKer A, Barta Z (2002) Effects of haematophagous mites on nestling house sparrows (Passer domesticus). Acta Parasitologica 47: 318-322.

Szabo K, Szalmas A, Liker A, Barta Z (2008) Adaptive host-abandonment of ectoparasites before fledging? Within-brood distribution of nest mites in house sparrow broods. Journal of Parasitology 94: 1038-1043. doi: 10.1645/ge-1150.1

Thompson JR, Wu G (1991) The effect of ketone-bodies on nitrogen-metabolism in skeletal-muscle. Comparative Biochemistry and Physiology B-Biochemistry \& Molecular Biology 100: 209-216. doi: 10.1016/0305-0491(91)90363-i

Totzke U, Fenske M, Huppop O, Raabe H, Schach N (1999) The influence of fasting on blood and plasma composition of herring gulls (Larus argentatus). Physiological and Biochemical Zoology 72: 426-437. doi: 10.1086/316675

VleCK CM, VleCK D (2002) Physiological condition and reproductive consequences in Adelie penguins. Integrative and Comparative Biology 42: 76-83. doi: 10.1093/icb/42.1.76

Voyvoda H, ERdogan H (2010) Use of a hand-held meter for detecting subclinical ketosis in dairy cows. Research in Veterinary Science 89: 344-351. doi: 10.1016/j.rvsc.2010.04.007

Wilder SM, Raubenheimer D, Simpson SJ (2016) Moving beyond body condition indices as an estimate of fitness in ecological and evolutionary studies. Functional Ecology 30: 108-115. doi: 10.1111/1365-2435.12460

Witteveen M, Brown M, Downs CT (2014) Does sugar content matter? Blood plasma glucose levels in an occasional and a specialist avian nectarivore. Comparative Biochemistry and Physiology a-Molecular \& Integrative Physiology 167: 40-44. doi: 10.1016/j.cbpa.2013.09.017

Zeugswetter F, Benesch T, Pagitz M (2007) Validation of the portable blood glucose meter FreeStyle Freedom (TM) for the use in cats. Wiener Tierarztliche Monatsschrift 94: 143-148.

Submitted: 3 March 2016

Received in revised form: 5 July 2016

Accepted: 30 July 2016

Editorial responsibility: Carolina Arruda Freire

Author Contributions: LMMA, TCO and LCSL desgned de experiments.LMMA and TCO conducted the experiments LMMA and LCSL analyzed the data and LMMA wrote the paper. Competing Interests: The authors have declared that no competing interests exist. 